\title{
Once-Daily versus Twice-Daily Tacrolimus in Kidney Transplantation: A Systematic Review and Meta-analysis of Observational Studies
}

\author{
Somratai Vadcharavivad ${ }^{1} \cdot$ Warangkana Saengram ${ }^{2} \cdot$ Annop Phupradit $^{3} \cdot$ Nalinee Poolsup $^{4}$. \\ Wiwat Chancharoenthana ${ }^{5,6}$
}

Published online: 26 November 2019

(c) The Author(s) 2019, corrected publication 2019

\begin{abstract}
Background Tacrolimus is the most commonly prescribed medication in initial immunosuppressive regimens to prevent acute rejection in kidney transplant recipients (KTRs). Tacrolimus was originally available as an immediate-release formulation (IR-Tac) given twice daily. Extended-release tacrolimus (ER-Tac) given once daily was later developed with the expectation of improved medication adherence. Data from observational studies, which compared outcomes between ER-Tac and IR-Tac in different populations of KTRs including those who are unlikely to be enrolled in randomized clinical trials, have been reported.

Purpose To evaluate the incidence of biopsy-proven acute rejection (BPAR) at 12 months together with other outcomes reported in observational studies among adult KTRs who received ER-Tac compared to IR-Tac.

Methods In accordance with the recommendations of the Cochrane Collaboration and the Meta-analysis of Observational Studies in Epidemiology, we systematically reviewed all observational studies that compared clinical outcomes between ER-Tac and IR-Tac in KTRs. The systematic searches were conducted on PubMed, EMBASE, Scopus, and Web of Science without language restriction. Reference lists were also searched and reviewed. Data were extracted for BPAR, graft survival, patient survival, estimated glomerular filtration rate (eGFR), serum creatinine ( $\mathrm{Scr}$ ), creatinine clearance $(\mathrm{CrCl})$, at different times after kidney transplantation (KT). A meta-analysis was performed to integrate the results from the eligible studies. This study is registered with PROSPERO, number CRD42019135705.

Results From the 1401 articles screened, 10 observational studies in KTRs who received tacrolimus were included. The pooled results showed significantly lower BPAR with ER-Tac than with IR-Tac at 12 months post-KT ( 5 studies, $n=659$; RR, $0.69 ; 95 \%$ CI $0.51-0.95 ; p=0.02 ; I^{2}=0 \%$ ). No significant differences in BPAR at other time points after KT were found. Graft survival, patient survival, Scr, and eGFR were comparable between groups at different times over approximately 1 year after transplantation.

Conclusions Based upon currently available evidence in observational studies, 30\% lower risk of BPAR was observed in ER-Tac group compared with IR-Tac group at 12 months post-KT, while there was no significant difference in BPAR risk at any other studied time points. No differences in graft- and patient-survival rates and kidney function were found. Given the limitations of observational studies to make causal inference, as well as quality limitations among the included studies, caution should be exercised in interpreting these findings.
\end{abstract}

\section{Introduction}

Tacrolimus, a calcineurin inhibitor (CNI) with potent immunosuppressive activity in inhibiting T-lymphocyte activation and proliferation, as well as T-helper-cell-dependent B cell response, has been widely used as a preferred CNI for prophylaxis of acute rejection after kidney transplantation (KT)

Somratai Vadcharavivad

somratai.v@pharm.chula.ac.th; somratai@gmail.com

Extended author information available on the last page of the article
[1]. Tacrolimus is available in innovator and non-innovator immediate-release, twice-daily formulations (IR-Tac), and two different extended-release, once-daily formulations (ERTac) produced using different technologies: MR-4 formulation [2, 3], and Meltdose formulation [4].

Different pharmacokinetic properties and dosage requirements to achieve similar blood concentrations have been observed among these tacrolimus formulations. In comparison with IR-Tac, a higher dosage of MR-4 ER-Tac is often required to maintain a similar tacrolimus trough concentration [5-7], whereas a lower dosage requirement of 


\section{Key Points}

Similar clinical outcomes of extended-release tacrolimus and immediate-release tacrolimus were found from the pooled results of well-designed randomized controlled studies, in which most of the included kidney transplant recipients were at low immunologic risk, while little is known about clinical outcomes of extended-release tacrolimus in comparison with immediate-release tacrolimus among high immunologic risk recipients.

One-third lower risk of rejection at 1-year post-kidney transplant was observed among recipients who received extended-release tacrolimus compared to immediaterelease tacrolimus when data were pooled from available observational studies in which wide spectrum of kidney recipients actually using tacrolimus therapy in routine clinical care were included.

The quality of currently available observational reports is considered sub-optimal; well-designed studies with longer time follow-up would be useful for optimizing tacrolimus therapy in kidney transplant recipients.

the Meltdose ER-Tac formulation has been demonstrated [8]. ER-Tac has been reported to provide less intra-patient variability of exposure [9] and increase convenience and self-reported adherence among kidney transplant recipients (KTRs) when compared to IR-Tac [10]. These advantageous properties of ER-Tac have garnered much interest since it was found that high intra-patient variability in tacrolimus exposure and nonadherence to tacrolimus treatment have been associated with poor long-term transplant outcomes [11-13]. However, a decrease in tacrolimus systemic exposure was observed following the conversion from IR-Tac to MR-4 ER-Tac $(1: 1 \mathrm{mg})$ in stable KTRs and a delay in reaching the target therapeutic range has been reported in de novo KTRs [14]. Underexposure to tacrolimus during the very early period post-transplantation, when the highest risk of allograft rejection is generally expected, is a clinical concern.

Based upon the evidence from randomized controlled trials (RCTs) comparing the efficacy and toxicity across different formulations in de novo KTRs, the impact on kidney allograft function appears to be comparable between ER-Tac and IR-Tac [15]. Of note, most of the studied KTRs were at low immunologic risk, possibly for ethical reasons. Highrisk KTRs such as re-transplant KTRs, ABO blood group incompatible (ABOi) kidney recipients, and pre-sensitized recipients were not included in most of the RCTs, in which inclusion and exclusion criteria are generally more stringent than patient characteristics normally seen in clinical practice. Observational studies may provide information on patients who are not likely to be enrolled in RCTs. Metaanalysis techniques, originally designed to combine data from RCTs, have been used to summarize evidence on an association from multiple observational studies in some KTR populations such as obesity KTRs and ABOi recipients [16-18].

Given that various induction therapies, potent maintenance immunosuppressive regimens with different steroid dosing strategies, and desensitization protocols together with newer, more subtle immunology tests are currently available, immunosuppressive regimens can be tailored to specific needs according to the immunological risk status of individual KTRs. In many transplant institutions, early immunosuppression options and long-term regimens are selected based upon a pre-transplant risk assessment and the post-transplant clinical course of each recipient.

Data from published observational studies comparing the effects of different formulations of tacrolimus may provide further insights into treatment patterns and outcomes for a more heterogenous patient population than those participating in RCTs. Inclusion of high risk KTRs, who are usually excluded from RCTs that are designed to evaluate the effects of tacrolimus formulations, may better reflect the wide spectrum of patients actually using the treatment in routine clinical care. In addition to filling the critical knowledge gaps, the results of appropriately designed observational studies should also be used for augmenting the information from RCTs and to evaluate the generalizability of the RCT findings.

The objective of this systematic review and meta-analysis is to evaluate the incidence of biopsy-proven acute rejection (BPAR) at 12 months post-KT, together with other outcomes of de novo KTRs who received ER-Tac compared to those who received IR-Tac after transplantation based on currently available evidence from reported observational studies.

\section{Methods}

\subsection{Data Sources and Search Strategy}

This systematic review and meta-analysis was conducted according to the recommendations of the Cochrane Collaboration and the Meta-analysis of Observational Studies in Epidemiology study $[19,20]$. The study protocol is available in the International Prospective Register of Systematic Review (PROSPERO): CRD42019135705. To identify potentially eligible studies, the electronic databases PubMed, EMBASE, Scopus, and Web of Science were systematically searched from inception to 15 May 2019. No language restrictions were applied. The following search terms were used: [kidney transplant* or renal transplant*] AND [extended-release tacrolimus or prolonged-release 
tacrolimus or once-daily tacrolimus or FK506E] AND [immediate-release tacrolimus or twice-daily tacrolimus or tacrolimus or FK506]. A historical search of relevant articles was undertaken, reference lists of reports were reviewed for potential additional studies, and personal contact with correspondents of the articles was made, if necessary.

\subsection{Eligibility Criteria}

The studies searched were included in this study if they: (a) were observational studies in de novo KTRs, including recipients undergoing re-transplantation, that reported clinical outcomes after ER-Tac and included an IR-Tac control group, and (b) reported one or more of the following measures: BPAR, graft survival and patient survival, estimated glomerular filtration (eGFR), creatinine clearance $(\mathrm{CrCl})$, and serum creatinine ( $\mathrm{Scr}$ ). Studies conducted with pediatric populations and those reported in abstract only, editorials, conference proceedings, and letters were excluded.

\subsection{Study Selection}

All identified studies in our literature search were screened for eligibility by two reviewers (WS, AP) independently. If either reviewer identified a citation as potentially relevant, the full text of the article was also obtained. The reviewers independently assessed the full texts of the selected studies to determine the appropriateness for inclusion. Any disagreement was resolved by consensus between the reviewers or adjudication with a third party (SV), if necessary. The reasons for exclusion were recorded at the full-text screening stage.

\subsection{Outcome Measures}

The primary outcome was the identification of studies reporting BPAR at 12 months after transplantation. The secondary outcomes comprised studies reporting BPAR within 6 months and after 12 months post-KT; graft survival and patient survival within 6 months, at 12 months and after 12 months post-KT; eGFR at 6,12 and after 12 months after transplantation, calculated from serum creatinine with the use of MDRD equation [21] or another method if eGFR estimated by the MDRD equation was not available; $\mathrm{CrCl}$ calculated by the Cockcroft-Gault equation [22] or measured by a 24-h urine collection at 6 and 12 months and after 12 months post-KT; and Scr reported in $\mathrm{mg} / \mathrm{dL}$ (Scr values reported in $\mu \mathrm{mol} / \mathrm{L}$ were converted to $\mathrm{mg} / \mathrm{dL}$ before pooling the results). Data reported in a graphic format were used only when the numerical data of the outcome of interest were not reported in the included studies.

\subsection{Data Extraction}

Using a standardized extraction form, two investigators (WS, AP) independently extracted the following data from each included study: demographic and clinical information, study design, eligibility criteria, and treatment outcomes. When duplicate reports of the same study or population were identified, the latest complete publication was selected. Any disagreement was resolved through discussion, or with consultation of a third party (SV or WC). When studies presented different estimates of the outcome of interest, the most precise or adjusted measures were extracted.

\subsection{Assessment of Risk of Bias}

The quality of each study was independently assessed by two investigators (WS, AP) using the ROBINS-I tool, assessing the following 7 domains: confounding, selection of participants, classification of intervention, deviations from intervention, missing data, measurement of outcome, and selection of reported results [23]. These domains were qualitatively classified as being at critical, serious, moderate or low risk of bias. A "no information" category was used only when insufficient data were reported to permit an assessment. The overall risk of bias of each study was considered as low if the risk of bias was low in all domains, as moderate if the risk of bias was low or moderate for all domains, as serious if the risk of bias was serious in at least one domain, as critical if the risk of bias was critical in at least one domain, or as no information when there was no clear indication as to whether the study was at serious or critical risk of bias and/or there was a lack of information in one or more domains. Disagreement was resolved by discussion and consensus or by the decision of a third party (SV).

\subsection{Statistical Analysis}

Statistical heterogeneity between studies was determined using Cochrane's $Q$ test. The $Q$ statistic at a level of 0.1 was considered as significant. The degree of heterogeneity was quantified using $I^{2}$ statistic. The $I^{2}$ index is the percentage of total variation across studies due to heterogeneity, which can be quantified as low $(<25 \%)$, moderate $(25-75 \%)$, and high (> 75\%) [24].

The treatment effects from multiple studies that reported the same outcomes were pooled to integrate the findings and provide combined estimates. For continuous data, the mean difference (MD) was calculated to estimate the amount by which ER-Tac changes the outcome on average compared with IR-Tac. The pooled estimates of discrete data were expressed as relative risk (RR) to compare the probability of an outcome occurring in KTRs who received ER-Tac as compared to those who received IR-Tac. The results were 
depicted by forest plots with a 95\% CI. The inverse varianceweighted method was used for the pooling of MD and RR. A random effects model was used to estimate the effect size for each outcome measure.

To evaluate publication bias, a funnel plot was constructed by plotting the RR of the primary outcome against the standard error (SE) of the logarithm of RR. Egger's test was used for detecting asymmetry in a funnel plot [25]. Sensitivity analysis was performed to assess whether the difference of ER-Tac starting techniques between early conversion to ER-Tac from IR-Tac within 10 days post-KT and de novo ER-Tac initiation affected BPAR incidence at 12 months after KT.

All analyses were performed using the Review Manager (RevMan) program, version 5.3 Copenhagen (The Nordic Cochrane Centre, The Cochrane Collaboration, 2014). Unless otherwise stated, a $p$ value of $<0.05$ was considered statistically significant.

\section{Results}

\subsection{Literature Search Results}

The initial electronic database search captured 1401 potential articles. After the exclusion of 568 duplicates, 833 titles and abstracts were screened. Then, 801 reports were further excluded, leaving 32 studies for eligibility evaluation. The majority of exclusions were made due to the articles being abstract-only publication, as described in Fig. 1. A total of 10 observational studies, with a total number of 1176 adult de novo KTRs, were included in this meta-analysis [26-35].

\subsection{Study Characteristics}

The characteristics of the included studies are summarized in Table 1. Mean age of studied populations, type of kidney transplantation and other characteristics of KTRs in each of these studies are presented in Table 2. All 10 studies reported the clinical outcomes of the MR-4 formulation of ER-Tac in comparison with IR-Tac in de novo KTRs. Almost all of the included KTRs received tacrolimus in combination with either mycophenolate mofetil (MMF) or mycophenolate sodium (MPS) and corticosteroids (CS) together with or without the use of anti-T lymphocyte globulin, alemtuzumab, or basiliximab for induction therapy. The use of intravenous immunoglobulins, rituximab with plasmapheresis or splenectomy were also reported in some studies [29-31, 33 , 35], as provided in Table 3. The reported outcomes of interest are shown in Table 4.

\subsection{Risk of Bias}

Of the 10 included observational studies in the review, only one [29] was considered of moderate quality when assessed using the ROBINS-I quality assessment tool. The other nine studies had serious overall risk of bias. Three studies were assessed as having serious risk of bias in both domains of confounding and of selection of participants into the studies. Six studies had a serious risk of bias due to either confounding or selection of participants for the studies, as presented in Fig. 2. The level of available evidence is currently sub-optimal.

\subsection{Biopsy-proven Acute Rejection Incidence at $\mathbf{1 2}$ Months after Kidney Transplantation}

There were 5 included studies that reported BPAR incidences in KTRs who received ER-Tac and IR-Tac at 12 months post-KT [29-31, 33, 35]. Based on the pooled results of these studies, the BPAR incidence was $15.7 \%$ in the ER-Tac group and $23.7 \%$ in the IR-Tac group. The calculated absolute risk difference was $8 \%$. A significant difference in BPAR was found between ER-Tac and IR-Tac at 12 months post-KT with the pooled RR of 0.69 ( 5 studies, $n=659 ; 95 \%$ CI $0.51-0.95 ; p=0.02$ ). A RR reduction of $31 \%$ was estimated. The results among these studies were homogenous ( $Q$ statistic, $p=0.61 ; I^{2}=0 \%$ ), as presented in Fig. 3. The Egger's test detected no evidence of publication bias (bias, -0.62 ; 95\% CI -3.74 to $2.48 ; p=0.478$; 4 studies, excluding 1 study with a zero rate in total). When the study in which KTRs received treatment conversion to ERTac from IR-Tac within 10 days post-KT [35] was excluded in the sensitivity analysis, no substantive change to the difference was observed ( 4 studies, $n=585$; RR, $0.70 ; 95 \% \mathrm{CI}$ $0.51-0.95 ; p=0.02 ; I^{2}=0 \%$ ).

\subsection{Biopsy-proven Acute Rejection Incidence at Other Time Points after Kidney Transplantation}

Two included studies reported comparable BPAR within the first 6 months post-KT $[30,31]$. One reported BPAR at 3 weeks [30], and the other at 3 months [31]. No significant difference in BPAR was observed among those who received the ER-Tac formulation in comparison with the IR-Tac within 6 months post-KT ( 2 studies, $n=164$; $\mathrm{RR}, 1.25$; 95\% CI $0.33-4.80 ; p=0.75 ; I^{2}=0 \%$ ), as presented in Fig. 3. There was only one study which reported BPAR at 24 months post-KT [34]. With a $16.6 \%$ (28 of 168 patients) conversion from IR-Tac to ER-Tac and 7.3\% (6 of 82 patients) conversion from ER-Tac to IR-Tac, BPAR incidences of $10.6 \%$ (11 of 104 patients) and 11.6\% (17 of 146 
Fig. 1 Study selection process

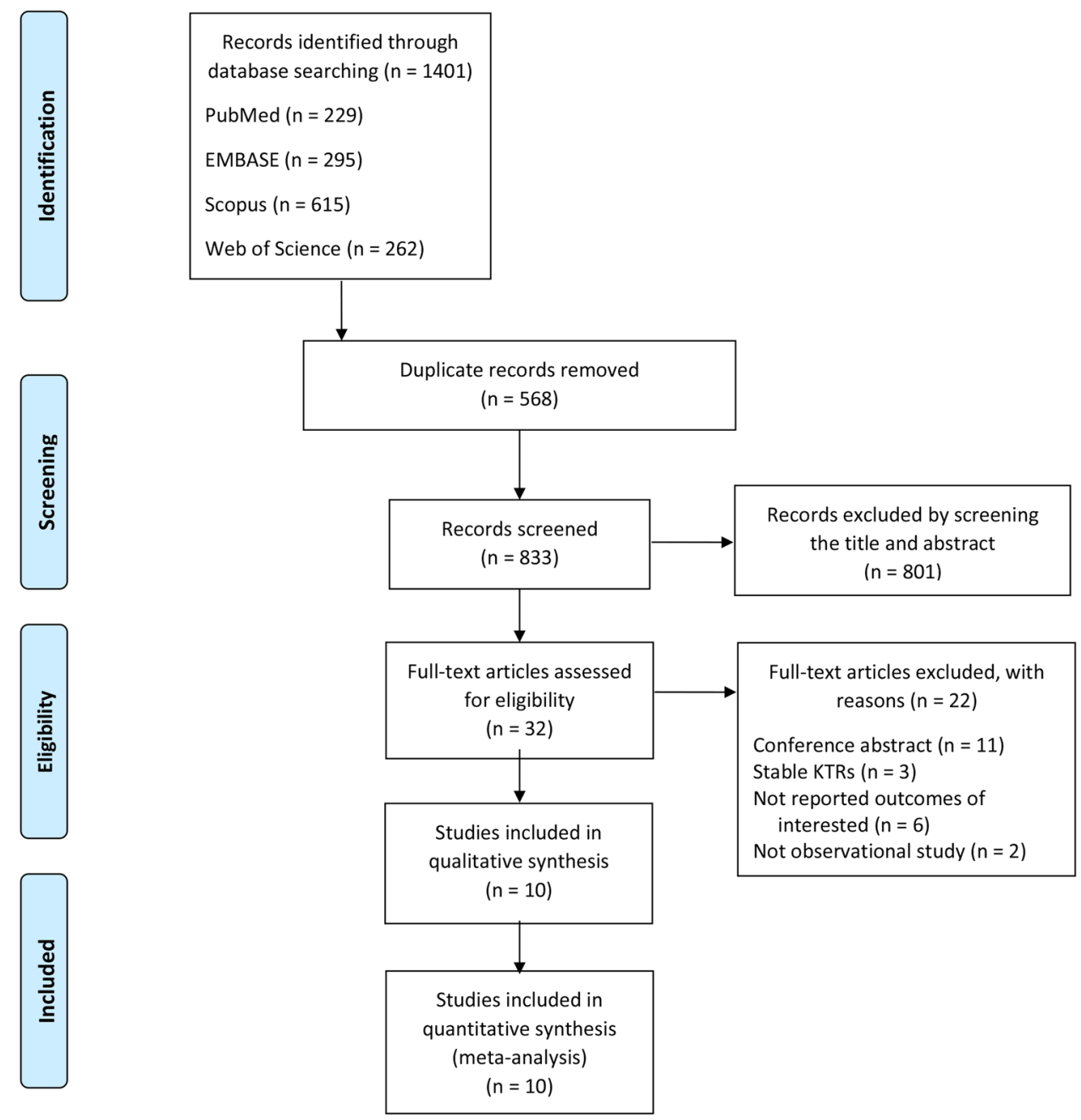

patients) were observed in those who received ER-Tac and IR-Tac at 24-month follow-up, respectively $(p=0.84)$ [34].

\subsection{Graft Survival}

Three included studies reported graft survival rates within the first 6 months post-KT [26-28]. Two studies reported graft survival at different follow-up times during the first 6 months post-KT $[27,28]$ and the other reported no graft loss at 6 months [26]. The reported graft survival rate within 6 months post-KT among KTRs who received ERTac was not significantly different from those who received IR-Tac (3 studies, $n=161$; RR, 1.01; 95\% CI 0.96-1.07; $p=0.68 ; I^{2}=0 \%$ ), as shown in Fig. 4. Graft survival rates at 12 months were reported in 4 included studies with an overall 1-year graft survival rate of $97.4 \%$ [29, 30, 32, 35]. The 1-year graft survival rate of KTRs who received ER-Tac was comparable to those who received IR-Tac (4 studies, $n=426$; RR, $1.01 ; 95 \%$ CI $0.98-1.04 ; p=0.50 ; I^{2}=0 \%$ ), as shown in Fig. 4. The graft survival rate after 12 months post-KT was reported in the only one small study in which a $100 \%$ graft survival rate was observed in both ER-Tac and IR-Tac groups at 15.7 months after transplantation [30].

\subsection{Patient Survival}

Two included studies reported patient survival rates within the first 6 months post-KT between KTRs who received ERTac and IR-Tac $[27,35]$. The reported patient survival rate within the first 6 months post-KT of KTRs who received ERTac was comparable with those who received IR-Tac (2 studies, $n=153$; RR, $0.99 ; 95 \%$ CI $\left.0.94-1.04 ; p=0.75 ; I^{2}=0 \%\right)$, as shown in Fig. 4. Of the 4 included studies that reported the patient survival rate at 12 months [29, 30, 32, 35], the overall patient survival rate at 12 months post-KT was $98.6 \%$ and the pooled RR was 1.00 (4 studies, $n=426$; $95 \% \mathrm{CI}$ $0.97-1.03 ; p=0.94 ; I^{2}=0 \%$ ), as shown in Fig. 4. A patient survival rate of $100 \%$ was also reported at 15.7 months after transplantation in one study [30]. 
Table 1 Characteristics of the included observational studies

\begin{tabular}{|c|c|c|c|c|c|c|c|c|}
\hline \multirow[t]{2}{*}{ Study ID } & \multirow[t]{2}{*}{ Country } & \multicolumn{3}{|c|}{ Number of participants } & \multirow[t]{2}{*}{ Study design } & \multicolumn{2}{|l|}{ Observational period } & \multirow[t]{2}{*}{ Follow-up duration } \\
\hline & & Total & ER-Tac & IR-Tac & & ER-Tac & IR-Tac & \\
\hline $\begin{array}{l}\text { Crespo et al. (2009) } \\
\text { [26] }\end{array}$ & Spain & 52 & 26 & 26 & Retro & N/A & $\begin{array}{l}\text { Immediately before } \\
\text { ER-Tac group }\end{array}$ & 6 months \\
\hline $\begin{array}{l}\text { Andrés et al. (2010) } \\
\text { [27] }\end{array}$ & Spain & 79 & 49 & 30 & Retro & N/A & N/A & $\begin{array}{l}\text { ER-Tac, } \\
3.5 \pm 25 \text { months } \\
\text { IR-Tac, } 4 \pm 2.6 \text { months }\end{array}$ \\
\hline $\begin{array}{l}\text { Jelassi et al. (2011) } \\
\text { [28] }\end{array}$ & France & 30 & 12 & 18 & Retro & $\begin{array}{l}\text { June 2007-March } \\
2010^{\mathrm{a}}\end{array}$ & & $\begin{array}{l}\text { ER-Tac, } 45 \pm 60 \text { days } \\
\text { IR-Tac, } 37 \pm 26 \text { days }\end{array}$ \\
\hline $\begin{array}{l}\text { Fanous et al. (2013) } \\
\text { [29] }\end{array}$ & Canada & 201 & 106 & 95 & Retro & July 2009-July 2010 & July 2008-July 2009 & 12 months \\
\hline $\begin{array}{l}\text { Ishida et al. (2013) } \\
\text { [30] }\end{array}$ & Japan & 45 & 10 & 35 & Retro & After February 2009 & Before February 2009 & $\begin{array}{l}\text { Mean } 15.7 \text { months } \\
\text { (range } 12.9- \\
18.5 \text { months) }\end{array}$ \\
\hline $\begin{array}{l}\text { Masutani et al. (2014) } \\
\text { [31] }\end{array}$ & Japan & 119 & 90 & 29 & Retro & $\begin{array}{l}\text { August 2008-April } \\
2011^{\mathrm{a}}\end{array}$ & & 12 months \\
\hline Fan et al. (2017) [32] & China & 106 & 45 & 61 & Retro & $\begin{array}{l}\text { May 2013-June } \\
2014^{\mathrm{a}}\end{array}$ & & 12 months \\
\hline $\begin{array}{l}\text { Niioka et al. (2017) } \\
\text { [33] }\end{array}$ & Japan & 220 & 80 & 140 & Retro & $\begin{array}{l}\text { June 2001-August } \\
2014^{\mathrm{a}}\end{array}$ & & 12 months \\
\hline $\begin{array}{l}\text { Hage et al. (2019) } \\
\text { [34] }\end{array}$ & France & 250 & 82 & 168 & Retro & $\begin{array}{l}\text { January } 2009- \\
\text { December } 2013^{\text {a }}\end{array}$ & & 24 months \\
\hline Ho et al. (2019) [35] & USA & 74 & 19 & 55 & Retro & $\begin{array}{l}\text { January 2012-June } \\
2016^{\mathrm{a}}\end{array}$ & & 12 months \\
\hline
\end{tabular}

ER-Tac extended-release tacrolimus, IR-Tac immediate-release tacrolimus, N/A no available information, Retro retrospective study

${ }^{\mathrm{a}}$ Information was reported only for the overall population

\subsection{Serum Creatinine}

Five studies reported Scr within 6 months post-KT [26-28, $31,33]$. One study reported comparable Scr in ER-Tac and IR-Tac groups of 1.25 (IQR 0.96-1.51) and 1.22 (IQR, $1.00-1.57)$ at 1-month post-KT [33]. Another study reported comparable Scr evolution at 6 months post-KT [28]. Based on the pooled results of the other studies, which reported mean and SD of Scr [26, 27, 31], there was no significant difference in Scr between ER-Tac and IR-Tac during the 6 months postKT ( 3 studies, $n=246$; MD,$-0.05 \mathrm{mg} / \mathrm{dL}$; 95\% CI -0.25 to $0.15 ; p=0.62 ; I^{2}=58 \%$ ), as shown in Fig. 5 . Of 2 studies which reported Scr at 12 months post-KT [31, 33], one reported similar Scr during the follow-up period $(p=0.1)$ [31] and the other reported comparable median Scr at 12 months post-KT of 1.27 (IQR 0.86-1.53) and 1.14 (IQR 0.85-1.33) in those who received ER-Tac and IR-Tac, respectively [33].

\subsection{Estimated Glomerular Filtration Rate}

Comparable means of GFR between the ER-Tac and IRTac groups at Day 3 and at Months 3, 6, 12, and 24 were reported in one included study in which eGFR of KTRs in the ER-Tac group was $57.97 \pm 21.74 \mathrm{~mL} / \mathrm{min}$ and those in the IR-Tac group was $58.26 \pm 21.01 \mathrm{~mL} / \mathrm{min}$ at 24 months post-KT [34]. No significant difference of eGFR between KTRs who received ER-Tac and those who received IRTac within 6 months post-KT was graphically reported [29]. Two included studies reported means of eGFR at 12 months post-KT [29, 32]. One study reported eGFR of $58.8 \pm 17 \mathrm{~mL} / \mathrm{min} / 1.73 \mathrm{~m}^{2}$ in KTRs who received ER-Tac versus $59.2 \pm 18 \mathrm{~mL} / \mathrm{min} / 1.73 \mathrm{~m}^{2}$ in those who received IRTac at 12 months post-KT ( $p=0.307)$ [29]; whereas the other reported eGFR of $68.4 \pm 12.8 \mathrm{~mL} / \mathrm{min} / 1.73 \mathrm{~m}^{2}$ in KTRs who received ER-Tac and $70.8 \pm 12.4 \mathrm{~mL} / \mathrm{min} / 1.73 \mathrm{~m}^{2}$ in those who received IR-Tac at 12 months post-KT [32]. Based on the pooled results of these studies, there was no significant difference in eGFR between ER-Tac and IR-Tac at 12 months postKT ( 2 studies, $n=307 ; \mathrm{MD},-1.37 \mathrm{~mL} / \mathrm{min} / 1.73 \mathrm{~m}^{2}[95 \%$ CI -4.80 to 2.07]; $p=0.44 ; I^{2}=0 \%$ ), as presented in Fig. 5 .

None of the included studies reported creatinine clearance.

\section{Discussion}

This is a systematic review and meta-analysis of the current available evidence from observational studies comparing ER-Tac and IR-Tac based on BPAR in de novo KTRs at 
Table 2 Characteristics of kidney transplant recipients among the included studies

\begin{tabular}{|c|c|c|c|c|c|c|c|c|}
\hline \multirow[t]{2}{*}{ Study ID } & \multicolumn{3}{|c|}{ Type of kidney transplantation ${ }^{a}$} & \multicolumn{2}{|c|}{ Recipient age (years) ${ }^{b}$} & \multicolumn{2}{|c|}{$\begin{array}{l}\text { Recipient gen- } \\
\text { der (male \%) }\end{array}$} & \multirow[t]{2}{*}{ Others } \\
\hline & & ER-Tac & IR-Tac & ER-Tac & IR-Tac & ER-Tac & IR-Tac & \\
\hline \multirow{4}{*}{$\begin{array}{l}\text { Crespo et al. } \\
(2009) \text { [26] }\end{array}$} & Living donor & $0 \%$ & $8 \%$ & \multirow[t]{4}{*}{$48.7 \pm 16.7$} & \multirow[t]{4}{*}{$49.1 \pm 13.1$} & \multirow[t]{4}{*}{69} & \multirow[t]{4}{*}{69} & Peak PRA: ER-Tac, $0.7 \pm 3.5 \%$; IR- \\
\hline & Deceased donor & $100 \%$ & $92 \%$ & & & & & Tac, $3.5 \pm 9.1 \%$ \\
\hline & Re-transplant & $19 \%$ & $19 \%$ & & & & & Caucasians $88 \%$ \\
\hline & $\begin{array}{l}\text { Non-heart-beating } \\
\text { donor }\end{array}$ & $4 \%$ & $12 \%$ & & & & & $\begin{array}{l}\text { Exclude: KTRs who received ATG or } \\
\text { had not reached } 3 \text { months post-KT }\end{array}$ \\
\hline $\begin{array}{l}\text { Andrés et al. } \\
\text { (2010) [27] }\end{array}$ & N/A & N/A & N/A & $54.0 \pm 18.0$ & $49.0 \pm 12.0$ & N/A & N/A & \\
\hline $\begin{array}{l}\text { Jelassi et al. } \\
\text { (2011) [28] }\end{array}$ & N/A & N/A & N/A & $51.0 \pm 12.0$ & $54.0 \pm 10.0$ & 67 & 72 & \\
\hline \multirow{3}{*}{$\begin{array}{l}\text { Fanous et al. } \\
\text { (2013) [29] }\end{array}$} & Living donor & $33 \%$ & $37 \%$ & \multirow[t]{3}{*}{$53.4 \pm 14.0$} & \multirow[t]{3}{*}{$52.6 \pm 13.2$} & \multirow[t]{3}{*}{60} & \multirow[t]{3}{*}{55} & Peak PRA: ER-Tac, $21.7 \pm 32.2 \%$; \\
\hline & Deceased donor & $67 \%$ & $63 \%$ & & & & & IR-Tac, $27.9 \pm 35.1 \%$ \\
\hline & Re-transplant & $8 \%$ & $7 \%$ & & & & & $\begin{array}{l}\text { Caucasians/Black/Asian/other: } \\
\text { ER-Tac, 55/11/28/5\%; IR-Tac, } \\
\text { 54/5/36/5\% }\end{array}$ \\
\hline \multirow{2}{*}{$\begin{array}{l}\text { Ishida et al. } \\
\text { (2013) [30] }\end{array}$} & Living donor & $100 \%$ & $100 \%$ & Mean 37.8; & Mean 47.0; & 70 & 80 & Japanese \\
\hline & ABOi & $30 \%$ & $40 \%$ & Range $17-62$ & Range 19-67 & & & $\begin{array}{l}\text { HLA mismatch, mean (range): ER- } \\
\text { Tac, } 2.5(1-5) \text {; } \\
\text { IR-Tac, } 2.9(0-6) \\
\text { Exclude: re-transplantation, KTRs } \\
\text { who had not reached 1-year post- } \\
\text { KT }\end{array}$ \\
\hline \multirow[t]{2}{*}{$\begin{array}{l}\text { Masutani et al. } \\
\text { (2014) [31] }\end{array}$} & Living donor & $100 \%$ & $100 \%$ & \multirow[t]{2}{*}{$42 \pm 15$} & \multirow[t]{2}{*}{$34 \pm 5$} & \multirow[t]{2}{*}{76} & \multirow[t]{2}{*}{57} & $\begin{array}{l}\text { Flow cytometric PRA: ER-Tac, } \\
\text { 12.2\%; IR-Tac, } 10.3 \%\end{array}$ \\
\hline & ABOi & $32 \%$ & $21 \%$ & & & & & $\begin{array}{l}\text { HLA mismatch: ER-Tac, } 2.8 \pm 1.4 \text {; } \\
\text { IR-Tac, } 2.6 \pm 1.6\end{array}$ \\
\hline \multirow{2}{*}{$\begin{array}{l}\text { Fan et al. (2017) } \\
\text { [32] }\end{array}$} & Living donor & $31 \%^{\mathrm{d}}$ & & Median, 42.0; & Median, 39.6; & \multirow[t]{2}{*}{67} & \multirow[t]{2}{*}{70} & DSA negative \\
\hline & Deceased donor & $69 \%^{\mathrm{d}}$ & & Range $21-59$ & Range 24-57 & & & $\begin{array}{l}\text { Reach 1-month post-KT } \\
\text { CYP3A5 nonexpressers: ER-Tac, } \\
\text { 33\%; IR-Tac, } 41 \% \\
\text { Exclusion: usage of medication or } \\
\text { food significantly influent tacroli- } \\
\text { mus concentration }\end{array}$ \\
\hline \multirow{2}{*}{$\begin{array}{l}\text { Niioka et al. } \\
\text { (2017) [33] }\end{array}$} & \multirow[t]{2}{*}{ N/A } & \multirow[t]{2}{*}{ N/A } & \multirow[t]{2}{*}{ N/A } & Median, 53; & Median, 45; & 61 & 61 & Japanese \\
\hline & & & & Range $40-60$ & Range 35-55 & $(64)^{\mathrm{e}}$ & & $\begin{array}{l}\text { Absence of pretransplant DSA } \\
\text { Exclusion: non-adherence, drug } \\
\text { interaction obviously affected CYP } \\
\text { and ABCB1 }\end{array}$ \\
\hline \multirow{2}{*}{$\begin{array}{l}\text { Hage et al. } \\
\text { (2019) [34] }\end{array}$} & Living donor & $21 \%$ & $22 \%$ & \multirow[t]{2}{*}{$55 \pm 13$} & \multirow[t]{2}{*}{$52 \pm 14$} & \multirow[t]{2}{*}{70} & \multirow[t]{2}{*}{68} & Non-HLA sensitized \\
\hline & Deceased donor & $79 \%$ & $78 \%$ & & & & & $\begin{array}{l}\text { No re-transplantation } \\
\text { No ABOi }\end{array}$ \\
\hline $\begin{array}{l}\text { Ho et al. (2019) } \\
\text { [35] }\end{array}$ & Re-transplant & $0 \%$ & $6 \%$ & $49.5 \pm 16.3$ & N/A & 63 & 62 & $\begin{array}{l}\text { ER-Tac group must continue the regi- } \\
\text { men for } \geq 3 \text { months. } \\
\text { Propensity score matched }{ }^{\mathrm{f}} \\
\text { PRA }<20 / 20-80 />80 \% \text { : ER- } \\
\text { Tac, } 73.7 / 15.8 / 10.5 \% \text {; IR-Tac, } \\
\text { 72.7/20.0/7.3\% } \\
\text { Non-Hispanic white/Non-Hispanic } \\
\text { black/Hispanic/Asians: ER-Tac, } \\
\text { 52.6/5.3/31.6/10.5\%; IR-Tac, } \\
\text { 38.2/25.5/27.3/9.1\% } \\
\text { No steroid after } 3 \text { months post-KT: } \\
\text { ER-Tac, 52.6\%; IR-Tac, } 67.3 \%\end{array}$ \\
\hline
\end{tabular}


Table 2 (continued)

$\overline{A B C B 1}$ adenosine triphosphate (ATP)-binding cassette sub-family B member 1, ABOi ABO blood group incompatible, $C Y P$ cytochrome P450, $D S A$ donor-specific antibodies, ER-Tac extended-release tacrolimus, IR-Tac immediate-release tacrolimus, $H L A$ human leukocyte antigen, $K T$ kidney transplantation, KTRs kidney transplant recipients, N/A no available information, $P R A$ panel reactive antibody

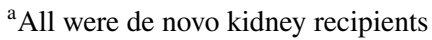

${ }^{\mathrm{b}}$ Data presented in mean \pm standard deviation or median (interquartile range) unless otherwise stated

${ }^{c}$ Four KTRs who had not reached 6 months post-KT were also excluded

${ }^{\mathrm{d}}$ Data were reported only for the overall population

${ }^{\mathrm{e}}$ When 14 kidney recipients who were given ER-Tac and treated with everolimus were not included

${ }^{\mathrm{f}}$ KTRs in IR-Tac group were propensity score matched for 15 demographic and clinical characteristics present at the time of their first transplantation

12 months after transplantation. The effects on other clinical outcomes at different times after transplantation were also evaluated. A comprehensive search was performed to identify all eligible studies published as of May 15th, 2019. Based on a thorough, systematic and recent review of the literature, 10 studies with a total number of 1176 KTRs were included. The pooled results of 5 included studies showed significant lower incidence of BPAR at 12 months post-KT in kidney recipients who received ER-Tac therapy compared with those who received IR-Tac ( 5 studies, $n=659$; RR 0.69, 95\% CI 0.51-0.95; $p=0.02)$ with no heterogeneity $\left(\mathrm{I}^{2}=0 \%\right)$ and no evidence of publication bias (Egger's test, $p=0.478$ ). There were no significant differences between the ER-Tac and IR-Tac groups with respect to incidence of BPAR at other time points after KT. Graft survival, patient survival, Scr and eGFR were comparable between the groups at different times over approximately 1 year after transplantation.

The various populations included in this current study reflect the wide spectrum of KTRs actually using tacrolimus for prophylaxis of allograft rejection in routine clinical care, including high immunologic risk patients, who are unlikely to be studied in an RCT, such as re-transplant KTRs, ABOi kidney recipients, and pre-sensitized recipients. Almost all of the KTRs in this study used a potent maintenance immunosuppressive regimen comprised of tacrolimus, mycophenolate and steroids. Strategies to reduce the risk of underexposure with ER-Tac during the early period post-KT, such as initiating tacrolimus therapy before transplantation, increasing the initial dose of ER-Tac, and early conversion from IR-Tac to ER-Tac when tacrolimus blood concentration is stable within the target range before hospital discharge, were applied in some of the studies, given that a lower trough blood concentration and/or higher dosage requirement to achieve the same concentration was observed among KTRs who received ER-Tac than among those who received IR-Tac in a Phase III noninferiority study [36]. Different induction therapies, pre-transplant desensitization strategies, and clinical and therapeutic drug monitoring approaches were also reported among the included studies.

Our finding of significant lower BPAR in ER-Tac (5 studies, $n=659$; RR $0.69,95 \%$ CI $0.51-0.95 ; p=0.02 ; I^{2}=0 \%$ ) compared with IR-Tac at 12 months post-KT is inconsistent with our previous meta-analysis of RCTs, in which no significant difference in BPAR at 12 months post-transplant was found between the 2 groups among low-to-moderate risk KTRs (4 trials, $n=1738$; RR 1.11; 95\% CI 0.88-1.44; $p=0.40 ; I^{2}=0 \%$ ) [15]. The difference in these findings may partly be explained by one or more of potential reasons, including a favorable impact of the ER-Tac formulation, a broader range of immunological risk, individualization in selection of induction therapy and pre-/peri-conditioning strategies, refinement in clinical and drug monitoring together with immunosuppressive drug dosage adjustment, and/or plausible bias in patient selection and uncontrolled confounders in the included observational studies.

Similar to the result of our previous meta-analysis [15], a significant difference in BPAR incidences within 6 months was not found in this current study. The impact of induction therapy, close monitoring during this high-risk period post$\mathrm{KT}$, and/or strategies of initiating ER-Tac therapy would at least in part explain the finding.

Even though the proportion of patients with BPAR at 1 year was significantly lower with ER-Tac, no significant differences in the patient- or graft-survival rate were observed between the 2 groups. Indeed, the current study showed comparable outcomes in both patient- and graftsurvival rates between ER-Tac and IR-Tac groups within 6 months, at 12 months and after 12 months post-KT. It has been reported that KTRs with acute rejection episodes had reductions in the estimated half-life of graft survival compared with those with no rejection episode (6.6 and 12.5 years, respectively) [37]. However, not all rejection episodes have the same impact on long-term kidney allograft function. Prompt recognition and evaluation of allograft dysfunction and timely intervention for acute rejection are the most important milestones for the recovery of graft function. If renal function completely returns to the baseline after treatment, the effects of the acute rejection would no longer have an impact on long-term graft survival [38, 39]. Of note, the 1-year patient- and graft-survival rates reported in all of the included studies were $95-100 \%$. The window of opportunity to improve these outcomes appears rather small. 


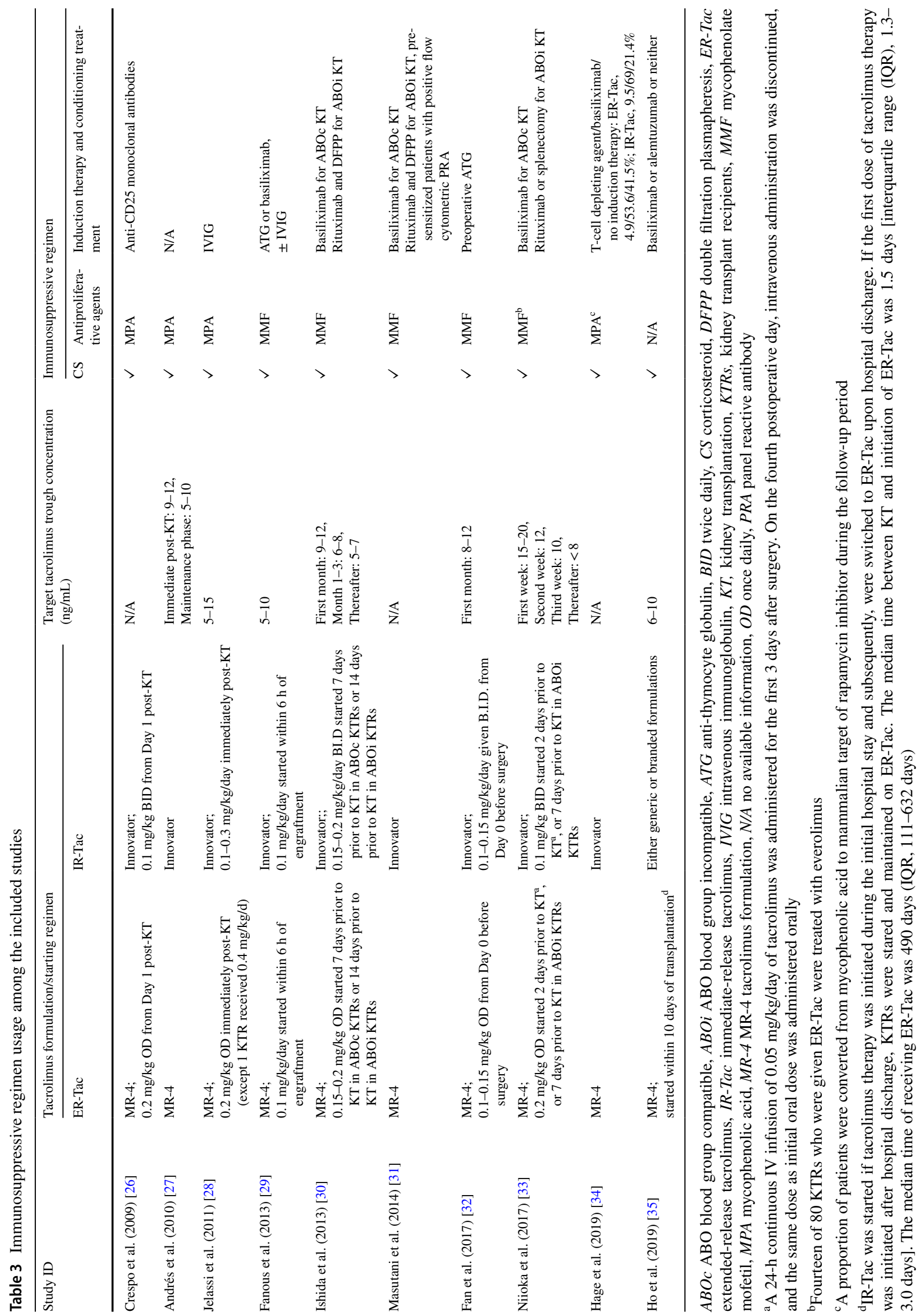


Based on the included studies, differences in the renal function effect, evaluated by eGFR or Scr, were not found between the two tacrolimus formulations within 6 months, at 12 months, and after 12 months post-KT. It should be also mentioned that the number of KTRs in the studies reporting these renal function outcomes is quite small and the long-term influence of the different formulations of tacrolimus on kidney allograft function in clinical practice is still questionable.

Consistent and homogenous results were observed in almost all of the outcomes studied in this meta-analysis. Only the $I^{2}$ of Scr reported within 6 months post-KT was higher than $25 \%$ (58\%), indicating a moderate variance in the observed Scr among various included studies. Therefore, interpretation of the pooled results of Scr within the first 6 months post-KT should be done with caution. Differences in factors such as donation from brain death donors [26] and marginal donors [26, 27] could have various consequences on kidney function post-KT. The marginal deceased donor kidney affects not only 2-year mean Scr levels [40] but is also considered as a risk factor for acute rejection [41]. Donor characteristics were not reported in a few of the included studies [28, 33, 35].

Although ER-Tac formulations were designed to promote a recipient's adherence to tacrolimus therapy by allowing a single morning dose once daily, Ho et al. [35] reported that there were KTRs who switched from ER-Tac to IR-Tac because of borderline changes on a protocol biopsy, supratherapeutic tacrolimus concentration on ER-Tac, and cost difference between branded ER-Tac and generic IR-Tac. Hage et al. [34] also reported that some KTRs requested to switch from IR-Tac to ER-Tac to improve their quality of life, while others were converted from ER-Tac to IR-Tac because high doses of ER-Tac were required to achieve the target trough level.

The pharmacokinetic profiles of IR-Tac, once-daily MR-4 ER-Tac, and once-daily Meldose ER-Tac differ, and these formulations are not bioequivalent [42]. Of the 10 included studies which reported the outcomes of interest, all included KTRs who received the MR-4 formulation of ER-Tac. Six of these studies reported a lower trough blood concentration or a higher dosage requirement of ER-Tac than IR-Tac to achieve comparable target trough concentrations [26, 27, 30-33]. Due to once-daily Meltdose ER-Tac release becoming more prevalent in more recent years, published data of this formulation regarding outcomes in clinical practice compared with those of the other tacrolimus formulations are still lacking.

Genetic variations in the gene-encoding cytochrome $\mathrm{P} 450$ (CYP) 3A5, the principle enzyme responsible for tacrolimus metabolism, significantly impacts tacrolimus exposure in KTRs. Not only are there higher dosage requirements for ER-Tac among heterozygous or homozygous carriers of a $C Y P 3 A 5^{*} 1$ allele (CYP3A5 expressers) compared with homozygous carriers of a $C Y P 3 A 5 * 3$ allele (CYP3A5 nonexpressers), but also a greater reduction in tacrolimus exposure has been reported in CYP3A5 expressers compared with CYP3A5 non-expressers in the early and stable states after kidney transplantation when the IR-Tac was converted to the once-daily ER-Tac formulation [43-46]. A possible explanation for the greater influence of CYP3A5 expression in the intestinal tract on the pharmacokinetics of ER-Tac than IR-Tac is that the prolonged-release characteristics of ER-Tac lead to more distal intestinal absorption and longer exposure of ER-Tac in the small intestine where the level of CYP3A5 protein expression varies depending on the genotype of CYP3A5 polymorphism [14, 45, 46]. Inclusion of KTRs with different ethnicities in this current meta-analysis may provide an advantage regarding generalizability to different groups of populations given that the allelic frequencies of the CYP $3 A 5^{*} 3$ single nucleotide polymorphism differ among individuals of different ethnicities [47].

Confounding bias is commonly considered as a major concern that can influence the result of observational studies. Among the included studies, tacrolimus therapy provided as part of routine clinical care to the included KTRs was simply observed. Although all of these studies are uniformly lacking randomization, key confounders were reported in most of them. Some studies also compared either measured confounders to report the level of covariate balance or proxy variables to mitigate concerns about unmeasured confounding. Propensity score matching, a confounding adjustment method, was used in the study reported by Ho et al. [35]. Of note, KTRs who did not reach a certain time point after KT were excluded in some studies [26, 30, 32, 35] and diversities in the measurement of the outcomes were found among studies, for instance, type of allograft biopsy (clinical indicated vs protocol biopsy) and version of the BANFF classification of allograft pathology [26, 27, 29].

The results of this study suggest that ER-Tac may provide a significant improvement in BPAR at 12 months post-KT compared with the IR-Tac, given that individualization of immunosuppressive strategy selection and refinement of immunosuppressant dosage regimen should be considered as important components of tacrolimus-based therapeutic intervention. In addition, it would be beneficial to identify characteristics of KTRs who may benefit most from the ERTac. However, further studies are needed to evaluate the long-term effects of the ER-Tac in clinical practice.

Our study has several limitations inherent with metaanalysis in observational studies in general and with studies of KT outcomes specifically. First, a few studies with small sample sizes were included in this meta-analysis. Second, the observational periods were no longer than 1 year in most of the included studies and, therefore, very limited information was available for evaluation of long-term outcomes 
Observational Studies of OD vs BID tacrolimus in Kidney Transplantation

1957

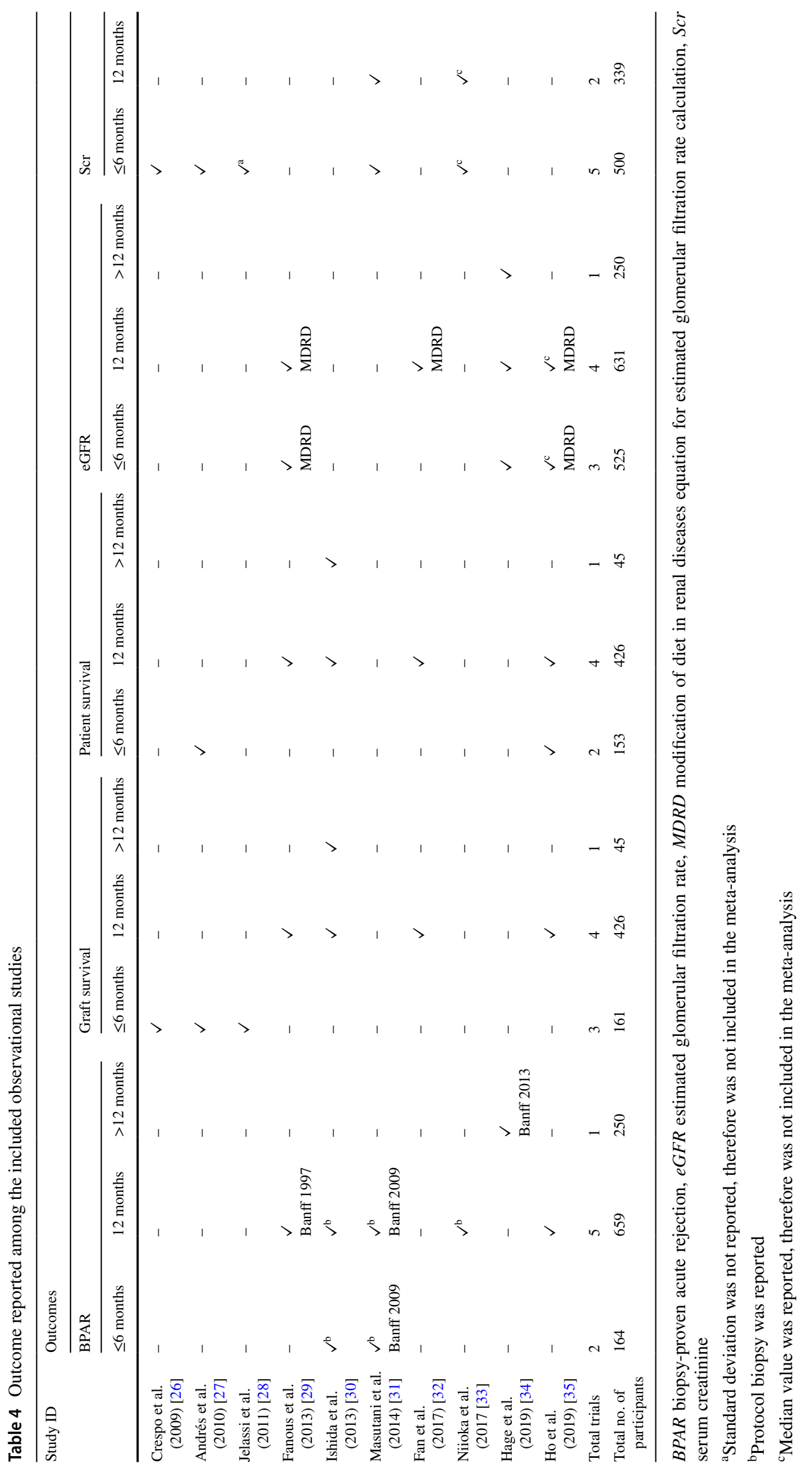

$\triangle$ dis 


\begin{tabular}{|c|c|c|c|c|c|c|c|c|}
\hline \multirow[b]{2}{*}{ Study ID } & \multicolumn{7}{|c|}{ Assessment within ROBINS-I risk of bias domains } & \multirow{2}{*}{$\begin{array}{c}\text { Overall } \\
\text { risk of bias } \\
\text { assessment }\end{array}$} \\
\hline & Confounding & $\begin{array}{l}\text { Selection of } \\
\text { participants } \\
\text { into the study }\end{array}$ & $\begin{array}{l}\text { Classification of } \\
\text { interventions }\end{array}$ & $\begin{array}{c}\text { Deviations from } \\
\text { intended } \\
\text { interventions }\end{array}$ & $\begin{array}{c}\text { Missing } \\
\text { data }\end{array}$ & $\begin{array}{l}\text { Measurement } \\
\text { of outcomes }\end{array}$ & $\begin{array}{l}\text { Selection of } \\
\text { the reported } \\
\text { result }\end{array}$ & \\
\hline $\begin{array}{l}\text { Crespo et al } \\
2009 \text { [26] }\end{array}$ & Serious & Serious & Moderate & Moderate & Low & Low & Low & Serious \\
\hline $\begin{array}{l}\text { Andres et al } \\
2010[27]\end{array}$ & Serious & Serious & Moderate & Moderate & Low & Low & Low & Serious \\
\hline $\begin{array}{l}\text { Jelassi et al } \\
2011[28]\end{array}$ & Serious & Serious & Moderate & Low & Low & Low & Low & Serious \\
\hline $\begin{array}{l}\text { Fanous et al } \\
2013[29]\end{array}$ & Low & Low & Low & Moderate & Low & Moderate & Low & Moderate \\
\hline $\begin{array}{l}\text { Ishida et al } \\
2013[30]\end{array}$ & Moderate & Serious & Moderate & Moderate & Low & Low & Low & Serious \\
\hline $\begin{array}{l}\text { Masutani et al } \\
2014[31]\end{array}$ & Serious & Moderate & Moderate & Low & Low & Low & Low & Serious \\
\hline $\begin{array}{l}\text { Fan et al } \\
2017[32]\end{array}$ & Low & Serious & Moderate & Low & Low & Low & Low & Serious \\
\hline $\begin{array}{l}\text { Niioka et al } \\
2017 \text { [33] }\end{array}$ & Serious & Low & Moderate & Serious & Moderate & Low & Low & Serious \\
\hline $\begin{array}{l}\text { Hage et al } \\
2019[34]\end{array}$ & Serious & Moderate & Moderate & Serious & Moderate & Low & Low & Serious \\
\hline $\begin{array}{l}\text { Ho et al } \\
2019[35]\end{array}$ & Low & Serious & Moderate & Moderate & Moderate & Moderate & Low & Serious \\
\hline
\end{tabular}

Categories for risk of bias assessments:
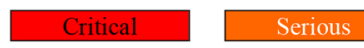

Moderate

Low

No Information

Fig. 2 Risk of bias of each of the included studies

\begin{tabular}{|c|c|c|c|c|c|c|c|c|c|c|c|}
\hline Study or Subgroup & \multicolumn{2}{|c|}{ ER-Tac } & \multicolumn{2}{|c|}{ IR-Tac } & \multicolumn{3}{|c|}{ Risk Ratio } & \multicolumn{4}{|c|}{$\begin{array}{c}\text { Risk Ratio } \\
\text { IV, Random, } 95 \% \mathrm{CI}\end{array}$} \\
\hline Ishida 2013 & 0 & 10 & 1 & 35 & $18.5 \%$ & $1.09[0.05,24.92]$ & 2013 & & & & \\
\hline Masutani 2014 & 8 & 90 & 2 & 29 & $81.5 \%$ & $1.29[0.29,5.73]$ & 2014 & & & & \\
\hline Total $(95 \% \mathrm{CI})$ & & 100 & & 64 & $100.0 \%$ & $1.25[0.33,4.80]$ & & & & & \\
\hline Total events & 8 & & 3 & & & & & & & & \\
\hline $\begin{array}{l}\text { Heterogeneity: } \mathrm{Tau}^{2}= \\
\text { Test for overall effect: }\end{array}$ & $\begin{array}{l}.00 ; \mathrm{Chi}^{2} \\
=0.32(\mathrm{~F}\end{array}$ & $\begin{array}{l}=0.01, \\
=0.75\end{array}$ & $\begin{array}{l}\mathrm{df}=1(\mathrm{P} \\
5)\end{array}$ & $=0.92$ & $; I^{2}=0 \%$ & & & 0.01 & $\begin{array}{l}0.1 \\
\text { Favours ER-Tac }\end{array}$ & $\begin{array}{l}10 \\
\text { Favours IR-Tac }\end{array}$ & 100 \\
\hline $\begin{array}{l}\text { b } \\
\text { Study or Subgroup }\end{array}$ & $\begin{array}{l}\text { ER-Ta } \\
\text { Events }\end{array}$ & $\begin{array}{l}\text { C } \\
\text { Total }\end{array}$ & $\begin{array}{l}\text { IR-Tac } \\
\text { Events }\end{array}$ & Total & Weight & $\begin{array}{c}\text { Risk Ratio } \\
\text { IV, Random, } 95 \% \mathrm{CI}\end{array}$ & Year & & $\begin{array}{r}\text { Risk } \\
\text { IV, Rando } \\
\end{array}$ & $\begin{array}{l}\text { Ratio } \\
\text { om, } 95 \% \mathrm{Cl}\end{array}$ & \\
\hline Fanous 2013 & 7 & 106 & 15 & 95 & $13.3 \%$ & $0.42[0.18,0.98]$ & 2013 & & & & \\
\hline Ishida 2013 & 0 & 10 & 0 & 35 & & Not estimable & 2013 & & & & \\
\hline Masutani 2014 & 15 & 90 & 7 & 29 & $15.3 \%$ & $0.69[0.31,1.53]$ & 2014 & & & & \\
\hline Niioka 2017 & 26 & 80 & 59 & 140 & $70.3 \%$ & $0.77[0.53,1.12]$ & 2017 & & & & \\
\hline Ho 2019 & 0 & 19 & 3 & 55 & $1.1 \%$ & $0.40[0.02,7.41]$ & 2019 & & & & \\
\hline Total $(95 \% \mathrm{Cl})$ & & 305 & & 354 & $100.0 \%$ & $0.69[0.51,0.95]$ & & & & & \\
\hline Total events & 48 & & 84 & & & & & & & & \\
\hline $\begin{array}{l}\text { Heterogeneity: } \mathrm{Tau}^{2}= \\
\text { Test for overall effect: }\end{array}$ & $\begin{array}{l}.00 ; \mathrm{Chi}^{2} \\
=2.30(\mathrm{P}\end{array}$ & $\begin{array}{l}=1.80 \\
=0.02\end{array}$ & $d f=3(P$ & $=0.61$ & $; I^{2}=0 \%$ & & & 0.01 & $\begin{array}{l}0.1 \\
\text { Favours ER-Tac }\end{array}$ & $\begin{array}{l}10 \\
\text { Favours IR-Tac }\end{array}$ & 100 \\
\hline
\end{tabular}

Fig. 3 Meta-analysis of biopsy-proven acute rejection incidence a within 6 months and $\mathbf{b}$ at 12 months post-kidney transplantation

after 1-year post-KT. Third, the study could have been influenced by various biases. For example, although different databases were comprehensively searched and publications in both English and other languages were considered, reporting bias cannot be ruled out. Also, even though all of our studied outcomes are objective parameters, performance bias may possibly exist. Selection bias may have occurred in non-randomized studies. Publication bias, which may lead to an under- or over-estimation of outcomes, also cannot be excluded. Fourth, most of the KTRs in this study received mycophenolate as a concomitant maintenance immunosuppressive agent, whether a combination regimen of tacrolimus 


\begin{tabular}{|c|c|c|c|c|c|}
\hline \multirow{2}{*}{$\begin{array}{l}\text { a } \\
\text { Study or Subgroup }\end{array}$} & \multicolumn{2}{|c|}{ ER-Tac } & \multicolumn{2}{|c|}{ IR-Tac } & \multirow[b]{2}{*}{ Weight } \\
\hline & Events & Total & Events & Total & \\
\hline Crespo 2009 & 26 & 26 & 26 & 26 & $61.9 \%$ \\
\hline Andres 2010 & 47 & 49 & 27 & 30 & $18.9 \%$ \\
\hline Jelassi 2011 & 12 & 12 & 18 & 18 & $19.2 \%$ \\
\hline Total $(95 \% \mathrm{CI})$ & & 87 & & 74 & $100.0 \%$ \\
\hline Total events & 85 & & 71 & & \\
\hline $\begin{array}{l}\text { Heterogeneity: } \mathrm{Tau}^{2}= \\
\text { Test for overall effect }\end{array}$ & $\begin{array}{l}.00 ; \mathrm{Chi}^{2} \\
=0.41\end{array}$ & $\begin{array}{l}=0.72 \\
=0.6\end{array}$ & df $=2(P$ & 0.7 & $;\left.\right|^{2}=0 \%$ \\
\hline
\end{tabular}

Risk Ratio

IV, Random, 95\% Cl Year

$1.00[0.93,1.08] 2009$

$1.07[0.93,1.22] 2010$

$1.00[0.88,1.14] 2011$

$1.01[0.96,1.07]$

Test for overall effect: $Z=0.41(P=0.68)$

b

ER-Tac

IR-Tac

Risk Ratio

Study or Subgroup Events Total Events Total Weight IV, Random, 95\% CI Year

$\begin{array}{lrrrrr}\text { Ishida } 2013 & 10 & 10 & 35 & 35 & 4.7 \% \\ \text { Fanous } 2013 & 103 & 106 & 90 & 95 & 26.0 \% \\ \text { Fan } 2017 & 45 & 45 & 61 & 61 & 60.3 \% \\ \text { Ho } 2019 & 19 & 19 & 52 & 55 & 9.0 \% \\ & & & & & \\ \text { Total }(95 \% \mathrm{Cl}) & 180 & & 246 & 100.0 \% \\ \text { Total events } & 177 & & \\ \text { Heterogeneity: } \text { Tau }^{2}=0.00 ; \mathrm{Chi}^{2}=0.91, \mathrm{df}=3(\mathrm{P}=0.82) ;\left.\right|^{2}=0 \% \\ \text { Test for overall effect: } \mathrm{Z}=0.68(\mathrm{P}=0.50)\end{array}$

$1.00[0.87,1.14] 2013$

$1.03[0.97,1.09] 2013$

$1.00[0.96,1.04] 2017$

$1.04[0.94,1.15] 2019$

$1.01[0.98,1.04]$

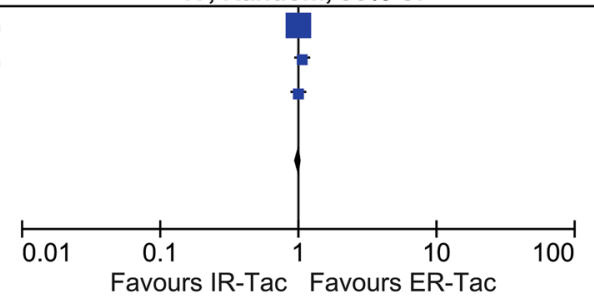

, Random, $95 \% \mathrm{Cl}$

C

ER-Tac IR-Tac Risk Ratio

Study or Subgroup Events Total Events Total Weight IV, Random, 95\% CI Year

$\begin{array}{llllllll}\text { Andres } 2010 & 48 & 49 & 30 & 30 & 55.7 \% & 0.99[0.92,1.05] & 2010\end{array}$

Ho $2019 \quad 19 \quad 19 \quad 55 \quad 55 \quad 44.3 \%$

$1.00[0.93,1.08] 2019$

Total $(95 \% \mathrm{Cl})$

68

$85100.0 \%$

$0.99[0.94,1.04]$

Total events $\quad 67 \quad 85$

Heterogeneity: $\mathrm{Tau}^{2}=0.00 ; \mathrm{Chi}^{2}=0.08, \mathrm{df}=1(\mathrm{P}=0.78) ; \mathrm{I}^{2}=0 \%$

Test for overall effect: $Z=0.31(P=0.75)$

d

\begin{tabular}{|c|c|c|c|c|c|}
\hline Study or Subgroup & Events & Total & Events & Total & Weight \\
\hline Fanous 2013 & 103 & 106 & 92 & 95 & $31.0 \%$ \\
\hline Ishida 2013 & 10 & 10 & 35 & 35 & $4.1 \%$ \\
\hline Fan 2017 & 45 & 45 & 61 & 61 & $51.7 \%$ \\
\hline Ho 2019 & 19 & 19 & 55 & 55 & $13.3 \%$ \\
\hline Total $(95 \% \mathrm{Cl})$ & & 180 & & 246 & $100.0 \%$ \\
\hline Total events & 177 & & 243 & & \\
\hline
\end{tabular}

Risk Ratio

IV, Random, 95\% Cl Year

$1.00[0.96,1.05] 2013$

$1.00[0.87,1.14] 2013$

$1.00[0.96,1.04] 2017$

$1.00[0.93,1.08] 2019$

$1.00[0.97,1.03]$
Risk Ratio

IV, Random, $95 \% \mathrm{Cl}$

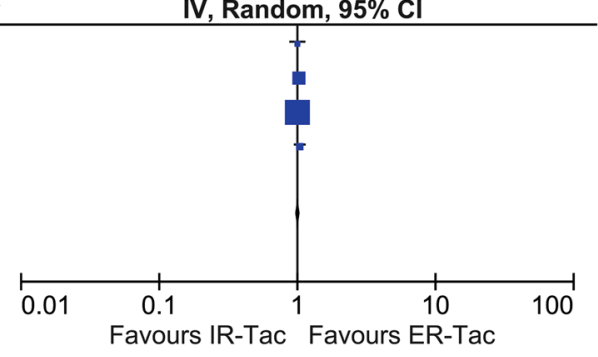
IV, Random, $95 \% \mathrm{Cl}$

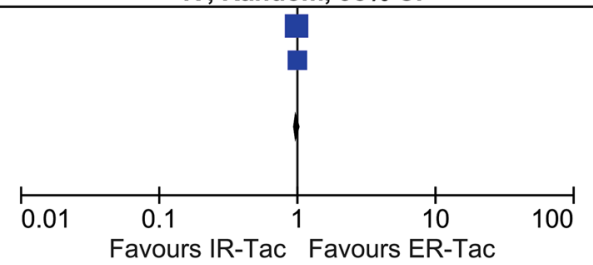

Favours IR-Tac Favours ER-Tac IV, Random, 95\% CI

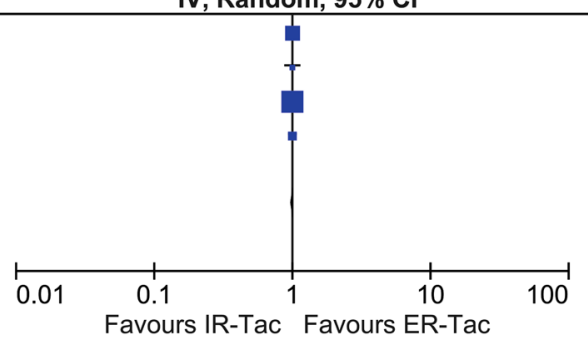

Fig. 4 Meta-analysis of a graft survival within 6 months, $\mathbf{b}$ graft survival at 12 months $\mathbf{c}$ patient survival within 6 months, and d graft survival at 12 months post-kidney transplantation

with other antiproliferative agents would have improved clinical outcomes of KTRs is questionable. Finally, our conclusions are based upon reported observational studies. Whether the different formulations of tacrolimus would impact these outcomes in a long-term follow-up and which populations of KTRs would benefit most from which formulations remain to be further explored.

\section{Conclusion}

Based upon currently available evidence in observational studies, ER-Tac is associated with a significant lower risk of BPAR at 12 months post-KT compared with IR-Tac, but there was no significant difference in BPAR at any other particular studied time points. No differences in graft- and patient-survival rates and kidney function were observed between the groups. Interpretation of these findings should be regarded with caution given that most of the included studies had serious overall risk of bias. It is plausible that 


\begin{tabular}{|c|c|c|c|c|c|c|c|c|c|}
\hline \multirow[b]{2}{*}{ Study or Subgroup } & \multicolumn{3}{|c|}{ ER-Tac } & \multicolumn{3}{|c|}{ IR-Tac } & \multirow[b]{2}{*}{ Weight } & \multicolumn{2}{|l|}{ Mean Difference } \\
\hline & Mean & SD & Total & Mean & SD & Total & & IV, Random, $95 \% \mathrm{CI}$ & Year \\
\hline Crespo 2009 & 2.2 & 1.4 & 24 & 1.66 & 0.59 & 24 & $9.3 \%$ & $0.54[-0.07,1.15]$ & 2009 \\
\hline Andres 2010 & 1.3 & 0.2 & 49 & 1.45 & 0.4 & 30 & $46.1 \%$ & $-0.15[-0.30,0.00]$ & 2010 \\
\hline Masutani 2014 & 1.18 & 0.42 & 90 & 1.25 & 0.38 & 29 & $44.6 \%$ & $-0.07[-0.23,0.09]$ & 2014 \\
\hline Total $(95 \% \mathrm{Cl})$ & & & 163 & & & 83 & $100.0 \%$ & $-0.05[-0.25,0.15]$ & \\
\hline
\end{tabular}

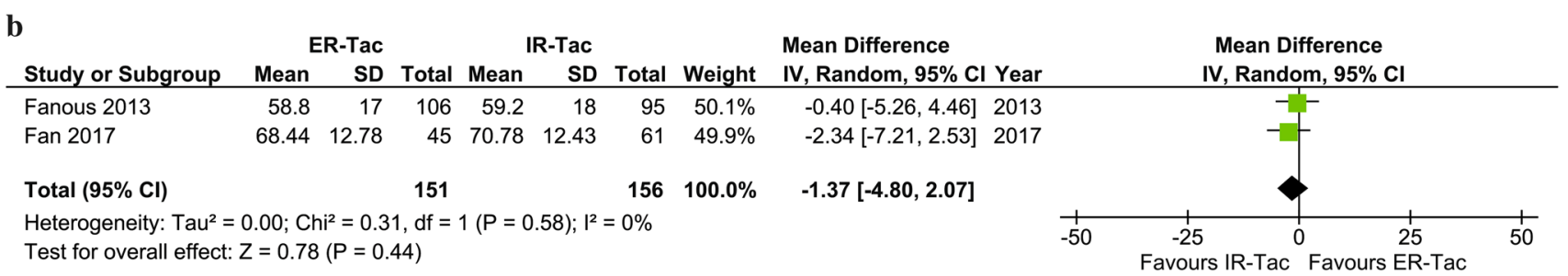

Fig. 5 Meta-analysis of a serum creatinine concentration within 6 months and b estimated glomerular filtration rate at 12 months post-kidney transplantation

the results could be biased or confounded by unmeasurable or uncontrollable factors. Data from this current study cannot provide convincing evidence of a causal relationship between exposure and outcome. Well-designed observational studies with longer-term follow-up involving highrisk patients could contribute to an improved understanding of the long-term effects of different tacrolimus formulations on allograft clinical outcomes in KTRs.

Acknowledgements This research received financial support from the Faculty of Pharmaceutical Sciences of Chulalongkorn University (Grant no. PHAR-2563-002). No pharmaceutical companies were involved in study design, data collection, data analysis or manuscript preparation.

Author Contributions SV conducted the selection process, data extraction, data analysis, result interpretation, and wrote the manuscript for submission. WS and AP conducted the literature search, selection process, data extraction, data analysis and results interpretation. All authors participated in the research design, discussions, and approved the manuscript for submission.

\section{Compliance with Ethical Standards}

Conflict of interest SV, WS, AP, NP, and WC declare no conflict of interest.

Open Access This article is distributed under the terms of the Creative Commons Attribution-NonCommercial 4.0 International License (http://creativecommons.org/licenses/by-nc/4.0/), which permits any noncommercial use, distribution, and reproduction in any medium, provided you give appropriate credit to the original author(s) and the source, provide a link to the Creative Commons license, and indicate if changes were made.

\section{References}

1. Disease Kidney. Improving Global Outcomes Transplant Work Group (KDIGO) clinical practice guideline for the care of kidney transplant recipients. Am J Transpl. 2009;9(Suppl3):S1-155.

2. First MR, Fitzsimmons WE. Modified release tacrolimus. Yonsei Med J. 2004;45(6):1127-31.

3. Chisholm MA, Middleton MD. Modified-release tacrolimus. Ann Pharmacother. 2006;40(2):270-5.

4. Grinyó JM, Petruzzelli S. Once-daily LCP-Tacro MeltDose tacrolimus for the prophylaxis of organ rejection in kidney and liver transplantations. Expert Rev Clin Immunol. 2014;10(12):1567-79.

5. de Jonge H, Kuypers DR, Verbeke K, Vanrenterghem Y. Reduced $\mathrm{C} 0$ concentrations and increased dose requirements in renal allograft recipients converted to the novel once-daily tacrolimus formulation. Transplantation. 2010;90(5):523-9.

6. Wu MJ, Cheng CY, Chen $\mathrm{CH}, \mathrm{Wu} \mathrm{WP}$, Cheng $\mathrm{CH}, \mathrm{Yu} \mathrm{DM}$, et al. Lower variability of tacrolimus trough concentration after conversion from prograf to advagraf in stable kidney transplant recipients. Transplantation. 2011;92(6):648-52.

7. Hougardy JM, Broeders N, Kianda M, Massart A, Madhoun P, LeMoine A, et al. Conversion from Prograf to Advagraf among kidney transplant recipients results in sustained decrease in tacrolimus exposure. Transplantation. 2011;91(5):566-9.

8. Gaber AO, Alloway RR, Bodziak K, Kaplan B, Bunnapradist S. Conversion from twice-daily tacrolimus capsules to once-daily extended-release tacrolimus (LCPT): a phase 2 trial of stable renal transplant recipients. Transplantation. 2013;96(2):191-7.

9. Stifft F, Stolk LM, Undre N, van Hooff JP, Christiaans MH. Lower variability in 24-hour exposure during once-daily compared to twice-daily tacrolimus formulation in kidney transplantation. Transplantation. 2014;97(7):775-80.

10. van Boekel GA, Kerkhofs CH, Hilbrands LB. Treatment satisfaction in renal transplant patients taking tacrolimus once daily. Clin Ther. 2013;35(11):1821-9.

11. Sellarés J, de Freitas DG, Mengel M, Reeve J, Einecke G, Sis B, et al. Understanding the causes of kidney transplant failure: the dominant role of antibody-mediated rejection and nonadherence. Am J Transpl. 2012;12(2):388-99.

12. Tielen M, van Exel J, Laging M, Beck DK, Khemai R, van Gelder $\mathrm{T}$, et al. Attitudes to medication after kidney transplantation 
and their association with medication adherence and graft survival: a 2-year follow-up study. J Transpl. 2014. https://doi. org/10.1155/2014/675301.

13. Shuker $N$, van Gelder $T$, Hesselink DA. Intra-patient variability in tacrolimus exposure: causes, consequences for clinical management. Transpl Rev (Orlando). 2015;29(2):78-84.

14. Barraclough KA, Isbel NM, Johnson DW, Campbell SB, Staatz CE. Once- versus twice-daily tacrolimus: are the formulations truly equivalent? Drugs. 2011;71(12):1561-77.

15. Saengram W, Vadcharavivad S, Poolsup N, Chancharoenthana W. Extended release versus immediate release tacrolimus in kidney transplant recipients: a systematic review and meta-analysis. Eur J Clin Pharmacol. 2018;74(10):1249-60.

16. Nicoletto BB, Fonseca NK, Manfro RC, Gonçalves LF, Leitão $\mathrm{CB}$, Souza GC. Effects of obesity on kidney transplantation outcomes: a systematic review and meta-analysis. Transplantation. 2014;98(2):167-76.

17. de Weerd AE, Betjes MGH. ABO-incompatible kidney transplant outcomes: a meta-analysis. Clin J Am Soc Nephrol. 2018;13(8):1234-43.

18. Scurt FG, Ewert L, Mertens PR, Haller H, Schmidt BMW, Chatzikyrkou C. Clinical outcomes after ABO-incompatible renal transplantation: a systematic review and meta-analysis. Lancet. 2019;393(10185):2059-72.

19. Cochrane Collaboration. Cochrane handbook for systematic reviews of interventions, version 5.1.0. 2016. http://handbook. cochrane.org/. Accessed 30 May 2016.

20. Stroup DF, Berlin JA, Morton SC, Olkin I, Williamson GD, Rennie D, et al. Meta-analysis of observational studies in epidemiology: a proposal for reporting. Meta-analysis Of observational studies in epidemiology (MOOSE) group. JAMA. 2000;283(15):2008-12.

21. Levey AS, Bosch JP, Lewis JB, Greene T, Rogers N, Roth D. A more accurate method to estimate glomerular filtration rate from serum creatinine: a new prediction equation. Ann Intern Med. 1999;130(6):461-70.

22. Cockcroft DW, Gault MH. Prediction of creatinine clearance from serum creatinine. Nephron. 1976;16(1):31-41.

23. Sterne JA, Hernán MA, Reeves BC, Savović J, Berkman ND, Viswanathan M, et al. ROBINS-I: a tool for assessing risk of bias in non-randomised studies of interventions. BMJ. 2016;355:i4919.

24. Higgins J, Thompson S, Deeks J, Altman D. Measuring inconsistency in meta-analyses. BMJ. 2003;327(7414):557-60.

25. Egger M, Davey Smith G, Schneider M, Minder C. Bias in meta-analysis detected by a simple, graphical test. BMJ. 1997;315(7109):629-34.

26. Crespo M, Mir M, Marin M, Hurtado S, Estadella C, Guri X, et al. De novo kidney transplant recipients need higher doses of Advagraf compared with Prograf to get therapeutic levels. Transpl Proc. 2009;41(6):2115-7.

27. Andrés A, Delgado-Arranz M, Morales E, Dipalma T, Polanco $\mathrm{N}$, Gutierrez-Solis E, et al. Extended-release tacrolimus therapy in de novo kidney transplant recipients: single-center experience. Transpl Proc. 2010;42(8):3034-7.

28. Jelassi ML, Lefeuvre S, Karras A, Moulonguet L, Billaud EM. Therapeutic drug monitoring in de novo kidney transplant receiving the modified-release once-daily tacrolimus. Transpl Proc. 2011;43(2):491-4

29. Fanous H, Zheng R, Campbell C, Huang M, Nash MM, Rapi L, et al. A comparison of the extended-release and standard-release formulations of tacrolimus in de novo kidney transplant recipients: a 12-month outcome study. Clin Kidney J. 2013;6(1):45-9.

30. Ishida K, Ito S, Tsuchiya T, Imanishi Y, Deguchi T. Clinical experience with once-daily tacrolimus in de novo kidney transplant recipients from living donors in Japan: 1-year follow up. Cent Eur J Urol. 2013;66(3):344-9.
31. Masutani K, Tsuchimoto A, Haruyama N, Kitada H, Okabe Y, Noguchi $\mathrm{H}$, et al. Protocol biopsy findings in living donor kidney transplant patients treated with once-daily or twice-daily tacrolimus formulation. Transpl Proc. 2014;46(2):395-9.

32. Fan B, Qiu K, Jiang Y, Hu X, Yin H, Wang W, et al. Prograf produces more benefits for CYP3A5 low expression patients in early stage after kidney transplantation. Biomed Pharmacother. 2017;88:738-44.

33. Niioka T, Kagaya H, Saito M, Inoue T, Numakura K, Yamamoto $\mathrm{R}$, et al. Impact of the CYP3A5 genotype on the distributions of dose-adjusted trough concentrations and incidence of rejection in Japanese renal transplant recipients receiving different tacrolimus formulations. Clin Exp Nephrol. 2017;21(5):787-96.

34. Hage V, Ferrandiz I, Belliere J, Esposito L, Hebral A, Cointault $\mathrm{O}$, et al. Incidence of donor-specific anti-HLA antibodies in NonHLA-sensitized patients given tacrolimus once or twice daily during the first 2 years after kidney transplant. Exp Clin Transpl. 2019;17(3):313-9.

35. Ho B, Bhagat H, Schwartz JJ, Atiemo K, Daud A, Kang R, et al. Real-World Study of once-daily, extended-release tacrolimus versus twice-daily, immediate-release tacrolimus in kidney transplantation: clinical outcomes and healthcare resource utilization. Adv Ther. 2019;36(6):1465-79.

36. Kramer BK, Charpentier B, Backman L, Silva HT Jr, Mondragon-Ramirez G, Cassuto-Viguier E, et al. Tacrolimus once daily (ADVAGRAF) versus twice daily (PROGRAF) in de novo renal transplantation: a randomized phase III study. Am J Transpl. 2010;10(12):2632-43.

37. Lindholm A, Ohlman S, Albrechtsen D, Tufveson G, Persson $\mathrm{H}$, Persson $\mathrm{NH}$. The impact of acute rejection episodes on longterm graft function and outcome in 1347 primary renal transplants treated by 3 cyclosporine regimens. Transplantation. 1993;56(2):307-15.

38. Madden RL, Mulhern JG, Benedetto BJ, O'Shea MH, Germain MJ, Braden GL, et al. Completely reversed acute rejection is not a significant risk factor for the development of chronic rejection in renal allograft recipients. Transpl Int. 2000;13(5):344-50.

39. Vereerstraeten P, Abramowicz D, de Pauw L, Kinnaert P. Absence of deleterious effect on longterm kidney graft survival of rejection episodes with complete functional recovery. Transplantation. 1997;63(12):1739-43.

40. Singh RP, Farney AC, Rogers J, Zuckerman J, Reeves-Daniel A, Hartmann E, et al. Kidney transplantation from donation after cardiac death donors: lack of impact of delayed graft function on post-transplant outcomes. Clin Transpl. 2011;25(2):255-64.

41. Wu WK, Famure O, Li Y, Kim SJ. Delayed graft function and the risk of acute rejection in the modern era of kidney transplantation. Kidney Int. 2015;88(4):851-8.

42. Staatz C, Tett S. Clinical pharmacokinetics of once daily tacrolimus in solid-organ transplant patients. Clin Pharmacokinet. 2015;54(10):993-1025.

43. Glowacki F, Lionet A, Hammelin JP, Labalette M, Provôt F, Hazzan M, et al. Influence of cytochrome P450 3A5 (CYP3A5) genetic polymorphism on the pharmacokinetics of the prolongedrelease, once-daily formulation of tacrolimus in stable renal transplant recipients. Clin Pharmacokinet. 2011;50(7):451-9.

44. Wehland M, Bauer S, Brakemeier S, Burgwinkel P, Glander P, Kreutz R, et al. Differential impact of the CYP3A5* 1 and CYP3A $5 * 3$ alleles on pre-dose concentrations of two tacrolimus formulations. Pharmacogenet Genom. 2011;21(4):179-84.

45. Niioka T, Kagaya H, Miura M, Numakura K, Saito M, Inoue T, et al. Pharmaceutical and genetic determinants for interindividual differences of tacrolimus bioavailability in renal transplant recipients. Eur J Clin Pharmacol. 2013;69(9):1659-65. 
46. Niioka T, Satoh S, Kagaya H, Numakura K, Inoue T, Saito M, et al. Comparison of pharmacokinetics and pharmacogenetics of once- and twice-daily tacrolimus in the early stage after renal transplantation. Transplantation. 2012;94(10):1013-9.
47. Chen L, Prasad GV. CYP3A5 polymorphisms in renal transplant recipients: influence on tacrolimus treatment. Pharmgenom Pers Med. 2018;11:23-33.

\section{Affiliations}

\section{Somratai Vadcharavivad ${ }^{1} \cdot$ Warangkana Saengram $^{2} \cdot$ Annop Phupradit $^{3} \cdot$ Nalinee Poolsup $^{4}$. Wiwat Chancharoenthana ${ }^{5,6}$}

1 Department of Pharmacy Practice, Faculty of Pharmaceutical Sciences, Chulalongkorn University, Bangkok 10330, Thailand

2 Pharmacy Department, Thammasat University Hospital, Pathumthani 12120, Thailand

3 Pharmacy Division, Ramathibodi Hospital, Mahidol University, Bangkok 10400, Thailand

4 Samrejvittaya School, Aranyaprathet, Sakaeo 27120, Thailand
5 Immunology Unit, Department of Microbiology, Faculty of Medicine, Chulalongkorn University, Bangkok 10330, Thailand

6 Nephrology Research Unit, Department of Clinical Tropical Medicine, Faculty of Tropical Medicine, Mahidol University, Bangkok 10400, Thailand 